\title{
A Cross-Cultural Approach to Understanding Entrepreneurial Intention
}

\author{
Juan A. Moriano ${ }^{1,}$ Marjan Gorgievski ${ }^{2}$, Mariola Laguna ${ }^{3}$, \\ Ute Stephan ${ }^{4}$, and Kiumars Zarafshani ${ }^{5}$ \\ ${ }^{1}$ Spanish University for Distance Education, UNED, Murillo, Spain \\ ${ }^{2}$ Erasmus University of Rotterdam, Rotterdam, Netherlands \\ ${ }^{3}$ The John Paul II Catholic University of Lublin, Lublin, Poland \\ ${ }^{4}$ Katholieke Universiteit Leuven, Leuven, Belgium \\ ${ }^{5}$ Razi University, Kermanshah, Iran \\ Forthcoming Journal of Career Development, \\ DOI: $10.1177 / 0894845310384481$
}

\section{Suggested citation:}

Moriano, J.A., Gorgievski, M., Laguna, M., Stephan, U. \& Zarafshani, K. (2011, published online first). A cross cultural approach to understanding entrepreneurial intention. Journal of Career Development. doi: 10.1177/0894845310384481

\section{Authors' Note}

The authors wish to thank Anisa Dohnre, Bohdan Roznowski and Linda Hagen for their contribution in collecting the data in India, Poland and Germany, respectively. The authors would also like to thank Professor Andrew Barkley for English language revision of this article. 


\title{
A cross-cultural approach to understanding entrepreneurial intention
}

\begin{abstract}
The present research aims to shed light on the role of culture in the formation of career intentions. It draws on the Theory of Planned Behavior (TPB, Ajzen, 1991), which has been widely employed to predict intentions, including entrepreneurial career intentions, but past research has almost exclusively been conducted in 'Western' countries. The present research specifically explores the extent to which both the strength of relationships of TPB predictors with entrepreneurial career intentions and the TPB predictors themselves are invariant across cultures. The study compares six very different countries (Germany, India, Iran, Poland, Spain, and The Netherlands) drawing on an overall sample of 1,074 students and their assessments of entrepreneurial career intentions. Results support culture universal effects of attitudes and perceived behavioral control (self-efficacy) on entrepreneurial career intentions, but cultural variation in the effects of subjective norm.
\end{abstract}

Keywords: Entrepreneurship; intention; culture; attitudes; self-efficacy 


\section{A cross-cultural approach to understanding entrepreneurial intention}

Researchers acknowledge the importance of the cultural context for career decisions (e.g. Brown, 2002; Lent, Brown \& Hackett, 2000). Important recent research into students' career decisions notes the role of cultural identity and cultural variation among diverse cultural groups within one country for career decision (e.g. Flores, Robitschek, Celebi, Andersen, \& Hoang, 2010; Leong, 2010) as well as country differences in the decision to pursue a career in management (Malach-Pines \& Kaspi-Baruch, 2008). This paper aims to add to the literature on culture and career intentions by asking whether known predictors of career intentions influence these intentions differentially depending on the cultural context, i.e. conceiving culture as a moderator of known relationships. More specifically, the present research explores intentions to become an entrepreneur in six countries drawing on the Theory of Planned Behavior (TPB) as one of the best-established theories to predict intentions, including career intentions. This research also explores whether the understanding, or meaning, of core concepts of the TPB varies across cultures. Thus, the paper aims to provide insights on whether the same theory can be applied across cultures to understand career intentions and if not which components of the theory are (not) universally applicable.

The current paper concentrates on entrepreneurial career intentions as entrepreneurship is considered one of the most important factors contributing to economic development and has numerous benefits for the society. It drives innovation, creates jobs, develops human potential, and satisfies new customer demands (European Commission, 2003; for a review see Van Praag \& Versloot, 2007). However, only a small percentage of the working population typically engages in entrepreneurship (e.g. Bosma, Acs, Autio, Coduras, \& Levie, 2008). Such evidence has compelled researchers to employ socio-cognitive models and theories to identify the antecedents of entrepreneurial intention, especially among young people planning their careers (van Gelderen et al., 2008). 
The decision to become an entrepreneur is a deliberate and conscious decision (Krueger, Reilly, \& Carsrud, 2000). Creating a new company requires time, involving both considerable planning and a high degree of cognitive processing (Baron, 2004). Thus, an entrepreneurial career decision can be considered the type of planned behavior for which intention models are ideally suited (Bird, 1988). Entrepreneurial intentions, in turn, are a deciding factor for performing entrepreneurial behavior (Kolvereid \& Isaksen, 2006).

This research embraces the TPB developed by Ajzen (1991), which takes into account personal and social factors to explain intentional behaviors. The TPB is an important sociocognitive theory that has been successfully applied in a wide variety of fields (e.g. Beck \& Ajzen, 1991; Harland, Staats, \& Wilke, 1999). It explains entrepreneurial intentions more detailed and consistently than alternative models (Krueger et al., 2000; van Gelderen et al., 2008). The TPB integrates two lines of research on entrepreneurial intentions: research on the relationships between attitudes and entrepreneurial intention (Douglas \& Shepherd, 2002), and research on the connections between self-efficacy and entrepreneurial intention (Jung, Ehrlich, De Noble, \& Baik, 2001). The TPB has been used successfully in the past to describe entrepreneurial intentions of students in the U.S. (Autio, Keeley, Klofsten, Parker, \& Hay, 2001; Krueger et al., 2000), The Netherlands (van Gelderen et al., 2008), Norway (Kolvereid, 1996), Russia (Tkachev\& Kolvereid, 1999), Finland, Sweden (Autio et al., 2001), Germany (Jacob \& Richter, 2005), Spain and Taiwan (Liñán \& Chen, 2009; Moriano, 2005), and South Africa (Gird \& Bagraim, 2008).

However, past research comparing the applicability of the TPB across different cultures has been limited in three ways. First, most previous research used TPB to analyze students' entrepreneurial intentions in specific countries or conducted cultural comparisons based on the ethnic background of participants within one country (e.g. van Gelderen et al., 2008). Second, only a few studies compared TPB across cultures (based on the same 
instrument), but these studies typically contrast only two countries (e.g. Spain and Taiwan; Liñán \& Chen, 2009). Third, the question of whether the TPB measures the same constructs across cultures has, to our knowledge, not been addressed in the context of entrepreneurship. This means that the meaning of TPB constructs in past reearch might not have been the same across cultures, i.e. cross-culturally non-equivalent (e.g., Steenkamp \& Baumgarnter, 1998). Hence, one may question whether the results of past cross-cultural comparisons are meaningful as the relationships may reflect systematic biases in individuals' interpretations and responses.

Therefore, this study seeks to extend the existing literature by examining the applicability of the TPB model in six different European and Asian countries (Germany, India, Iran, Poland, Spain, and The Netherlands) and test whether relationships between TPB components are invariant across cultures. It seeks to avoid the pitfalls of previous research, by using multi-group structural equation modeling techniques that allow for testing the crosscultural equivalence of the measured concepts prior to hypotheses testing. Such a test of cross-cultural concept equivalence allows to establish, whether concepts have the same meaning across cultures, the importance of which has been emphasized lately in career studies (Behrend, Thompson, Meade, Newton, \& Grayson, 2008).

\section{Theory of Planned Behavior Explaining Entrepreneurial Intentions}

Intentionality as well as forethought are acknowledged to be core features of human beings (Bandura, 2001). Intention constitutes a representation of the direction of future action. It affects individuals' choices as well as directs and maintains behavior. Research to date in areas as diverse as health-related behavior, voting behavior, spare-time activity, or job seeking demonstrates that intention is a strong predictor of behavior (see Armitage \& Conner, 2001 for a review).

Entrepreneurial intention is defined as the conscious state of mind that precedes action 
and directs attention towards a goal such as starting a new business (Bird, 1988; Krueger \& Carsrud, 1993). Forming an intention to develop an entrepreneurial career is the first step in the often long process of venture creation (Gartner, Shaver, Gatewood, \& Katz, 1994). Several models aim to explain entrepreneurial intentions such as the Entrepreneurial Event Model of Shapero (1982), the Model of Implementing Entrepreneurial Ideas (Bird, 1988) or Maximization of the Expected Utility (Douglas \& Shepherd, 2002). Although these models represent a step forward in entrepreneurial behavior research, they have not been as influential as the TPB (Autio et al., 2001; Krueger et al., 2000; van Gelderen et al., 2008; Tkachev \& Kolvereid, 1999). Unlike other models, the TPB offers a coherent and generally applicable theoretical framework, which enables us to understand and predict entrepreneurial intention by taking into account not only personal but also social factors (Krueger et al., 2000). As such, personal history and characteristics and skills can predispose individuals towards entrepreneurial intentions, as well as the social context (social support and culture). However, according to the TPB, only the three TPB components - attitude towards behavior, subjective norms, and perceived behavioral control - predict behavioral intentions directly. All other factors are theorized to influence intentions through these three components.

The attitude towards behavior within the TPB is defined as an individual's overall evaluation of a behavior (Ajzen, 1991). Previous studies on the subject of entrepreneurial intention have measured attitudes by using only one item, which focuses on the personal interest in starting a business (Autio et al., 2001; Krueger et al., 2000). However, single-item measures are prone to measurement unreliability (DeVellis, 1991). According to the TPB, the attitude toward a behavior is determined by the total set of accessible behavioral beliefs linking the behavior to various outcomes and other attributes. In addition, the strength of each belief is weighted by the evaluation of the outcomes (Ajzen, 1991). Thus, two people may hold an equally strong belief that entrepreneurship involves facing new challenges, but one of 
them may view these challenges positively while the other may consider them unpleasant. This two-element process of attitude formation allows us to explain why persons holding different beliefs may exhibit identical attitudes, and vice versa.

The second component of the TPB is the subjective norm, which is defined as the individual's perception of the social pressures to engage (or not to engage) in entrepreneurial behavior (Ajzen, 1991). The subjective norm consists of two components: normative beliefs and the motivation to comply with these beliefs (Ajzen \& Fishbein, 1980). Normative beliefs concern the perceived probability that important referent individuals or groups will approve or reject a given behavior; they set the norm that specifies how the subject should behave. The second component, motivation to comply, reflects a person's willingness to conform to these norms, i.e. to behave in keeping with the expectation of important referents. Depending on the social environment, these pressures can become a trigger or a barrier to the development of an entrepreneurial career.

The third TPB component, perceived behavioral control (PBC), refers to people's perceptions of their ability to perform a given behavior. Individuals usually choose to perform behaviors that they think they will be able to control and master. This concept is therefore very similar to self-efficacy (or even the same, see Bandura, 1982). Both concepts concerned the perceived ability to perform a behavior, e.g., starting a new business. In their review of TPB, Armitage and Conner (2001) conclude that self-efficacy is more clearly defined and more strongly correlated with intentions than PCB. In fact, self-efficacy has replaced PBC in numerous studies (Krueger et al., 2000; Kolvereid \& Isaksen, 2006; Moriano, 2005; van Gelderen et al., 2008), and a recent meta-analysis showed that it is strongly positively related to business creation and entrepreneurial success (Rauch \& Frese, 2007).

The intention to perform a given behavior constitutes the central element of TPB (Ajzen, 1991) - the stronger the intention to perform a given behavior, the greater the 
probability of its effective performance. Reviews of existing research show that intention accounts for approximately $30 \%$ of the variance in behavior (Armitage \& Conner, 2001). Furthermore, past research shows that the individual TPB components (attitude, social norm, PBC) in turn together explain between 21\% (Autio et al., 2001) and 55\% (Liñán \& Chen, 2009) of the variance in the intention to develop an entrepreneurial career. However, the strength of their influence on intention varies from study to study.

To sum up, past research confirms the legitimacy of using TPB to explain entrepreneurial intention across various cultures, although the cultures researched were mainly 'Western' cultures. Hence, our first hypotheses pertain to the replicability of the TPB across a wider range of cultures, namely four European countries (Germany, Poland, The Netherlands and Spain) and two Asia countries (India and Iran).

Hypothesis 1: Entrepreneurial intention relates positively to positive attitudes toward entrepreneurship (Hypothesis 1a) supportive subjective norms (Hypothesis 1b); and high PBC (Hypothesis 1c).

\section{Cultural differences and the Theory of Planned Behavior}

Cultural differences in entrepreneurship are known to exist and manifest themselves, e.g. in consistent national differences in entrepreneurial activity (e.g. Bosma et al., 2008). With regard to TPB, Ajzen (1991) expects that all three components of TPB, attitudes, social norm and $\mathrm{PBC}$, predict intentions and in turn behaviors equally well across different samples and cultures (see also Hypothesis 1). He also posits that this holds for intentional behaviors in general. However, theory and some empirical findings give reason to expect that the strength of relationships among the TPB components might be moderated by culture. We will first discuss theoretical reasons before reviewing related empirical findings.

Lent et al. (2000) suggest that the immediate personal environment (e.g., significant others) as well as the broader socio-cultural context (e.g., societal culture) influence an 
individual's career choice. Specifically, the broader socio-cultural context is assumed to exert its influence through the immediate personal environment on career choice decisions. With regard to entrepreneurial career decisions it thus seems plausible that culture influences entrepreneurial intentions through social norms, which are linked to the immediate personal environment (Lent et al., 2000). Similarly, Krueger (2000) argues that culture influences intentions primarily through the influence on the 'social' component in the TPB model, i.e. subjective norms.

Culture is defined as "the collective programming of the mind that distinguishes the members of one group or category of people from another" (Hofstede, 2001, p. 9). Cultural values and practices have been found to moderate relationships between the TPB constructs (Hagger et al., 2007). One of the main dimensions on which cultures vary is individualism and collectivism (e.g. Hofstede, 2001; Oyserman \& Lee, 2008; Triandis, 1995). People from the "more individualistic" countries of Western Europe consider themselves as autonomous, more differentiated from others and independent from social groups, compared with people in "more collectivistic" countries. The Eastern European countries and Asia are considered more collectivistic, and people tend to perceive themselves using a sociocentric perspective, which is socially sensitive, more interdependent and less differentiated, i.e. pursuing group rather then personal goals (Markus \& Kitayama, 2003; Oyserman \& Lee, 2008). In other words, while people from individualistic cultures rely mainly on themselves to make judgments and decisions, people from collectivistic cultures are more likely to comply with the expectations of their immediate group (House, Hanges, Javidan, Dorfman, \& Gupta, 2004). This suggests that in collectivist cultures the consideration of the expectation of close others and the motivation to comply with such expectations - in short the subjective norm - will have a relatively stronger influence on the intention to become an entrepreneur than in individualistic cultures (see also Begley \& Tan, 2001; Tiessen, 1997). 
First empirical evidence supports these assumptions. For example, Abrams, Ando, and Hinkle (1998) found a closer association of subjective norm with intention to leave an organization in a collectivistic culture (Japan) compared with an individualistic culture (UK). Although no studies to date test similar effects with regard to predicting entrepreneurial intentions, a review of past research suggests that culture may indeed moderate the extent to which social norms influence entrepreneurial intentions. Studies conducted in individualistic cultures generally fail to find an effect of social norm on entrepreneurial intention. For instance, Autio et al. (2001) researching students in Scandinavian countries and the U.S. found $\mathrm{PBC}$ to be most closely associated with entrepreneurial intention, whereas subjective norm was not a significant predictor. Similarly, Krueger et al. (2000) found that attitude and PBC, but not subjective norm, were significantly related with U.S. students' entrepreneurial intention. In contrast, Tkachev and Kolvereid (1999) found subjective norm to be a significant predictor of entrepreneurial intentions in a collectivistic country (Russia).

The most recent large-scale cultural study - the GLOBE study (House et al., 2004) found Iran and India to be among the countries with the highest (in-group) collectivism (measured as societal practices). Poland and Spain still exhibited rather high in-group collectivism practices, while Germany and The Netherlands were among the most individualistic countries. Taking country of origin as a proxy of culture - admittedly not an ideal way of operationalizing culture - we hypothesize the following:

Hypothesis 2: Subjective norm will be more strongly associated with entrepreneurial intention in more collectivistic cultures (such as India, Iran, and also Poland and Spain) than in less collectivistic cultures (such as Germany and The Netherlands).

\section{Method}

\section{Sample}

Participants in this study are 1074 students (mean age $24.24 ; S D=4.52$ ) from 
Universities in six different countries. Table 1 shows subsample characteristics. The sample from Germany (Marburg) consisted of 217 master students. The mean age for the sample was $23.93(S D=2.26)$. The sample from India (Gurgaon) consisted of 86 students (mean age 31.49; $S D=6.41)$. The sample from Iran (Kermanshah) consisted of 114 students (mean age 21.09; $S D=1.66$ ). In the Polish sample (Bydgoszcz and Lublin), 291 students took part (mean age 22.25; SD = 1.73). In Spain (Madrid), 227 students participated (mean age 27.16; $S D=5.05)$. In The Netherlands (Rotterdam), 139 students took part in the study (mean age $22.12, S D=2.78)$. The samples differed significantly regarding their age $\left(F_{(5 / 1068 d f)}=159.49\right.$; $p<.001$ ), gender, employment status and the major students were enrolled in (see Table 1).

\section{Procedure}

Participation in the study was voluntary. In some countries, students received credit points for their participation. All questionnaires were completed anonymously to ensure confidentiality. Questionnaires were completed in the classroom (paper and pencil version; Germany, Iran, Poland) or over the Internet (India, Spain, The Netherlands).

The questionnaire was originally developed in Spanish. In each country, all items were translated using a translation-back-translation (Hambleton, 1994) or collaborative-iterative translation (Douglas \& Craig, 2007) methods to ensure that item-meaning was preserved through the translation process. Students from Germany, Iran, The Netherlands, Poland and Spain responded to the questionnaire in their native language. Students from India filled in the questionnaire in English.

\section{Measurement Instruments}

The Entrepreneurial Intention Questionnaire (EIQ) was originally developed in Spain by Moriano (2005). The EIQ comprises four subscales: attitudes towards entrepreneurship, subjective norms, $\mathrm{PBC}$, and entrepreneurial intention. Unlike other questionnaires used in the field (Autio et al., 2001; Krueger et al., 2000; Liñán \& Chen, 2009), EIQ follows Ajzen’s 
(2002a) methodological recommendations of how to construct a TPB questionnaire using composite measures of attitudes and subjective norms. The Cronbach alpha reliability of the EIQ subscales in previous research ranged from .76 to .87 in Spanish sample of 281 students and from .77 to .87 in Polish sample of 154 students (Laguna, Moriano, Roznowski, \& Gómez, 2008). The factorial structure of the instrument was also confirmed $\left(\chi^{2} / \mathrm{df}=1.78\right.$, GFI $=.92, \mathrm{CFI}=.96, \mathrm{RMSEA}=.05$ for Spanish sample; $\chi^{2} / \mathrm{df}=1.69, \mathrm{GFI}=.90, \mathrm{CFI}=.93$, RMSEA $=.06$ for Polish sample). All items in the questionnaire were measured on a 7-point Likert Scale (from 1 to 7). The EIQ instrument is available from the first author on request. Attitudes towards entrepreneurship were measured with two sets of six items that assess expected outcomes of an entrepreneurial career as well as desirability of these outcomes (Crohnbach's alpha for the current total sample .77). Following Ajzen (2002a), outcome expectations were multiplied by their desirability and then divided by ten to obtain scale average scores, with higher scores reflecting more positive attitudes towards an entrepreneurial career.

Subjective norms were measured with two sets consisting of three items each measuring how significant others (e.g. parents) would view their entrepreneurial career choice as well as their motivation to comply with these reference people (alpha .87). These two sets were multiplied and then divided by ten to obtain average scale scores. Higher scores are reflective of greater subjective norms.

The EIQ measures $P B C$ through entrepreneurial self-efficacy in line with other research on entrepreneurial intentions (Krueger et al., 2000; Kolvereid \& Isaksen, 2006; Moriano, 2005; van Gelderen et al., 2008). In this study, we used a five-item entrepreneurial self-efficacy scale (alpha .80). High scores indicate high entrepreneurial self-efficacy.

Entrepreneurial intention was measured using a four-item scale (alpha .86) in which each item assesses the perceived likelihood of an individual to choose an entrepreneurial 
career. Higher scores reflect stronger entrepreneurial intentions.

\section{Analyses}

The current study applies structural equation modeling (SEM) using Amos 6.0 (Arbuckle, 2006). An advantage of SEM over hierarchical regression analyses is that it tests relationships between latent constructs instead of observed constructs, i.e. it partials measurement error out of the observed constructs. Prior to testing our hypotheses of whether predictor variables are equally strong predictors of entrepreneurial intentions across cultures, we tested whether the pre-condition for such a comparison of strengths of relationships was met (van de Vijver \& Leung, 2001). More specifically, we tested three types of measurement invariance: (1) configural invariance (similar pattern of significant and non-significant factor loadings), (2) metric invariance (similar factor loadings), (3) and similarity of variances of the latent constructs (Steenkamp \& Baumgartner, 1998). To meaningfully compare relationships across groups, the measurement of constructs need to show at least partial metric invariance, and the variances of the predictor and outcome variables would need to be similar (e.g. Steenkamp \& Baumgartner, 1998). The term "partial" refers to at least two observed indicators of a latent construct showing invariance. In examining measurement invariance we constrain factor loadings and variances of the latent constructs to be equal across groups and compare this constrained model with the unconstrained one.

The goodness-of-fit of the models was evaluated using the $\chi^{2}$ goodness-of-fit statistic, the Non-Normed Fit Index (NNFI) and the Comparative Fit Index (CFI). The model $\chi^{2}$ higher values reflect the worse model's correspondence to the data. For both relative fit-indices, as a rule of thumb, values greater than .90 are considered as indicating a good fit (Byrne, 2001, pp. 79-88). In addition, the Root Mean Square Error of Approximation (RMSEA) is computed for which values up to .08 indicate a reasonable fit of the model (Browne \& Cudeck, 1992). 
Descriptive results concerning the study variables are presented in Table 2. Note that the purpose of our study was to compare the strength of relationships across cultures, and not mean differences. Thus, the mean differences that are presented here need to be interpreted with caution (e.g. Steenkamp \& Baumgartner, 1998; van de Vijver \& Leung, 2001).

\section{Testing Preconditions for Cross-Cultural Comparisons: Measurement Equivalence across Cultures}

As outlined above, prior to testing our hypotheses, we employed multi-group SEM techniques (confirmatory factor analyses) to test whether the preconditions for cross-cultural comparison are met, i.e. whether at least partial measurement requirements can be established across cultures. Models assuming only configural invariance were compared to subsequent nested models additionally assuming partial and full metric invariance (see Table 3).

In regards to configural invariance, the results of the factor analyses show that all items are significantly related to the underlying latent constructs that they were hypothesized to measure, and not to other latent constructs, with one exception. In Iran, the item "With what probability do you consider to create your own business from present to five years from now" was not significantly related to the factor measuring entrepreneurial intentions $(\beta=.19 ; \mathrm{B}=$ $.24 ; \mathrm{SE}=.16)$. Second and regarding metric invariance, constraining all item-factor-loadings to be equal across sub-samples leads to a significant deterioration of model fit for all scales. Table 3 shows the results per scale, which are discussed in the next paragraphs.

The findings can be attributed to the following items. Concerning attitudes towards entrepreneurship, two items on the attitude factor showed no measurement invariance, and hence their factor loading was estimated freely for at least one country (see Appendix 1 for the measurement instrument). This was the item "facing new challenges," which loaded weaker on the latent variable "attitudes towards entrepreneurship" in India and Iran, as compared to Germany, The Netherlands, Spain and Poland. Item loadings were estimated 
freely for the former two countries. Moreover, the factor loading of this item was below the recommended .50 for $\operatorname{Iran}(\beta=.41, \mathrm{~B}=.44, \mathrm{SE}=.11)$. Additionally, the item "obtaining a high income" had a weaker factor loading in Germany, as compared to the other countries ( $\beta$ $=.25, \mathrm{~B}=.41, \mathrm{SE}=.13)$. All other factor loadings were well above .50 .

Concerning subjective norm, parents' subjective norm towards becoming an entrepreneur loaded weaker on the latent factor of subjective norm for Poland, whereas subjective norm of classmates had lower factor loadings for Germany. All factor loadings were well above .50 for all countries.

For the entrepreneurial self-efficacy scale, only one item-loading was significantly different across countries: the expectation of being effective in defining ones' own business idea and strategy for the company loaded significantly lower on the latent factor "entrepreneurial self-efficacy" in Germany than in the other 5 countries. All factor loadings were well above the .50 threshold.

Finally, three of four items in the analyses measuring entrepreneurial intentions had different factor loadings in one or two of the countries. As was mentioned before, in Iran, the item "With what probability do you consider to create your own business from present to five years from now" was not significantly related to the factor measuring entrepreneurial intentions, whereas in India it related somewhat stronger to the factor than in other countries. In Spain, the item "Do you think that in the future you will create your own company" loaded significantly higher on the factor "entrepreneurial intentions.” In Germany, the item "Nevertheless, considering your actual situation and the limitations towards your options, indicate which career is more probably to be chosen" had a significantly higher factor loading than in the other countries.

Third, we tested whether the variances of attitude, subjective norm, PBC and entrepreneurial intention differed across cultures. We found that only the variance of attitudes 
towards entrepreneurship differed across cultures $\left(\Delta \chi^{2}\left({ }_{5} d f\right)=28.35, p<.001\right)$. It was higher in $\operatorname{Iran}(\operatorname{Var}=.96 ; \mathrm{SE}=.18)$, Spain $(\operatorname{Var}=.81 ; \mathrm{SE}=.12)$ and Poland $(\operatorname{Var}=.74 ; \mathrm{SE}=.10)$, and lower in India $(\operatorname{Var}=.53 ; \mathrm{SE}=.12)$, The Netherlands $(\operatorname{Var}=.48 ; \mathrm{SE}=.09)$ and Germany $(\operatorname{Var}=.35 ; \mathrm{SE}=.06)$.

To sum up, we found that the prerequisite for a meaningful test of cultural differences in the strength of relationships are overall met, i.e. we found at least partial measurement equivalence (Steenkamp \& Baumgartner, 1998). However, two findings need to be taken into account when interpreting the final results. First is the non-significant loading of one intentions item on its corresponding factor in Iran, indicating a slight difference in the meaning of intentions in Iran compared to the other cultures. Second, the variance in entrepreneurial attitudes differs significantly across countries.

\section{Hypotheses Tests: Predicting Entrepreneurial Intentions}

To test our hypotheses, we examined the relationships between attitudes toward entrepreneurship, subjective norms and PBC on the one hand, and entrepreneurial intentions on the other hand. We controlled for gender, age, employment status and major. Table 4 shows the results for the total sample and all subgroups. The model fits the data reasonably well: overall model fit is $\chi^{2}(179 d f)=786,23, p<.001 ; \mathrm{CFI}=.93$; NNFI $=.90, \mathrm{RMSEA}=.06$. In order to test differences between samples, multi-group SEM analyses were performed. Thus, the model is tested simultaneously in all samples, which allows testing for differences in relationships among TPB constructs across samples (Brown, 2006). The model for the multi group analyses also fits the data reasonably well: $\chi^{2}(920 \mathrm{df})=1580.71, p<.001$; CFI $=$ $.92 ; \mathrm{NNFI}=.88 ; \mathrm{RMSEA}=.03)$. The power of the single group and multi group analyses are good, respectively .96 and 1.00 .

Results provide partial support for the predictions concerning specific relationships between TPB components. For the whole sample, attitudes towards entrepreneurship 
(Hypothesis 1a), subjective norms (Hypothesis 1b) and entrepreneurial self-efficacy (Hypothesis 1c) are all significant predictors of entrepreneurial intentions. However, multigroup analyses show significant differences in predictive power of subjective norm between countries $\left(\Delta \chi^{2}(5 d f)=12.48, \mathrm{p}<.05\right)$. Paths leading from subjective norms (Hypothesis $\left.1 \mathrm{~b}\right)$ toward entrepreneurial intentions are only significant in two of the six countries, namely India, and The Netherlands, and marginally significant $(p<.10)$ in Spain and Iran. No differences were found in the predictive power of attitudes $\left(\Delta \chi^{2}(5 d f)=2.43\right.$, n.s. $)$ and entrepreneurial self-efficacy $\left(\Delta \chi^{2}(5 d f)=6.42, \mathrm{~ns}\right)$. Hence, Hypothesis 1a and 1c were confirmed, but Hypothesis $1 \mathrm{~b}$ was only partially supported.

Finally, according to Hypothesis 2 subjective norms have stronger effects on entrepreneurial intentions in collectivistic countries (India, Iran, Spain and Poland) than in individualistic countries (Germany and The Netherlands). Results do not support this hypothesis. Subjective norms are most closely associated with entrepreneurial intentions in The Netherlands and India (see Table 4).

\section{Discussion}

This study aimed to contribute to our understanding of how culture might affect career decisions. It specifically tested the cross-cultural generalizability of the TPB for predicting students' entrepreneurial intentions in six different countries. The present study improved upon past research by carefully testing pre-conditions for cross-cultural comparisons and modeling cross-cultural comparisons of the TPB with advanced SEM techniques. Moreover, we tested whether cultural differences in individualism/collectivism could account for differences in the relative importance of subjective norms found in past research.

Prior to hypotheses testing, we tested the assumptions of cross-cultural configural and partial metric measurement invariance - a necessary prerequisite for meaningful cross-cultural comparisons of relationships. We found only few deviations and no direct violation of the 
assumption of cross-cultural invariance. Like assumptions of statistical techniques, conditions for cross-cultural equivalence are almost never fully met in empirical data (e.g., van de Vijver \& Leung, 2001). Hence, similar minor deviations are quite typical for cross-cultural research and were also found in other studies examining the TPB model in different cultures, for example in the context of physical activity (Hagger et al., 2007). Thus our research supports the view that cross-cultural differences in the meaning of TPB components are generally minor in nature and hence TPB can be regarded a culture-universal theory, which can be meaningfully employed to predict career intentions in different countries.

Moreover, our study supports the notion that the relationships among the TPB components are equally strong and comparable across cultures - the only exception being the relation of social norms with intentions. Across cultures, attitudes toward entrepreneurship were the strongest predictor of entrepreneurial intentions, followed by entrepreneurial selfefficacy. Subjective norms appeared to be the least important predictor of students' entrepreneurial intentions across cultures and the only predictors whose influence varied across cultures. However, this cultural variation was not as predicted in our second hypotheses, i.e. the influence of social norms did not vary along the countries' collectivism individualism as hypothesized. Rather social norms significantly predicted entrepreneurial intentions in The Netherlands (an individualistic country) and India (a collectivistic country, cf. House et al., 2004). However, this finding is consistent with the results of another study using TPB to predict intentions to engage in physical activity in young people (Hagger et al., 2007), in which a similar hypothesis was also not supported. We could also rule out differences in demographic characteristics of the Dutch sample as an alternative explanation.

The generally weak influence of social norms on entrepreneurial intentions might also be due to the fact that younger people make entrepreneurial career decisions more based on personal (attitudes, self-efficacy) rather than social (subjective norm) considerations (cf. 
Autio et al., 2001; Krueger et al., 2000). Despite the theoretical importance of subjective norms (e.g. Ajzen, 1991), past meta-analytic research also found subjective norms to be least closely associated with behavioral intentions (e.g. Armitage \& Connor, 2001). To explain this finding, Armitage and Connor (2001) point to poor measurement and the need to conceptualize subjective norms more broadly. Given the care taken in the current study to develop the subjective norms measure in strict compliance with Ajzen's recommendations, the second explanation seems more plausible. Future research should explore further which referent groups are relevant in various cultures. For instance the current conceptualization seems in itself culture-bound by considering only the closest family members and friends as a significant referent group, while in more embedded, collectivistic culture the extended family is known to be highly influential (e.g. House et al., 2004). This would partially explain why relations of social norm with intentions are largely non-significant, i.e. because our measure may not have include all relevant 'significant others'.

Rather than operationally defining culture through country of data collection, future studies should employ direct measures of culture, such as shared perceptions of cultural practices or cultural values (e.g. Stephan \& Uhlaner, 2010). This study's findings also suggest that other cultural dimensions than individualism/collectivism may influence the development of entrepreneurial intention. For instance, across 40 countries Stephan and Uhlaner (2010) found that a more specific cultural dimension, i.e. the cultural desirability of entrepreneurship predicted national entrepreneurship rates. Regarding the general influence of culture on career decision, this research in connection with the present research seems to suggest that specific careers might be more or less legitimate to pursue in some cultures vs. others and this legitimacy of a certain career might be reflected in the social norm (i.e. in the beliefs of significant others whether or not an entrepreneurial career should be pursued). Future research might benefit from explicitly measuring such legitimacy of careers when applying the TPB 
across cultures. As one reviewer suggested, challenge, creativity, innovation, high-income and independence that are typically seen as the attractive aspects of an entrepreneurial career, might well be pursued through other careers such as management - particularly if a culture does not regard being an entrepreneur favorably.

\section{Limitations and Further Suggestions for Future Research}

A unique contribution of this study to the literature is the methodologically rigorous cross-cultural evaluation of the TPB model's generalizability - along with its core components and postulated relations between components - in the context of students' entrepreneurial career decisions. The study's strengths are the use of standardized measures for all TPB components and entrepreneurial intentions and the rigorous testing of the theoretical model in a sample of six countries.

There are still some limitations of the current study. First, the study did not apply a random sampling technique. Study participants were students from different universities, but not randomly chosen. Also given the aim of the study, i.e. to test students' entrepreneurial career intentions, all participants were students. This may, however, impose limits on the generalizability of the research findings to other groups. Future research may examine the relationships between TPB constructs, entrepreneurial intention and subsequent behavior with other samples than students and across other cultures.

The study used a self-report questionnaire of TPB components. The measure was carefully designed, taking into account Ajzen's (2002a) suggestion, and the use of confirmatory factor analysis allowed controlling for measurement error. However, a selfreport questionnaire is not an objective measure. On the other hand, it is not easy to recognize subjective personal beliefs another way then by asking people about them. Another limitation of our study is that it focused on the first step in the entrepreneurial process, i.e. predicting entrepreneurial intentions as most psychological studies conducted to 
date do (e.g. van Gelderen et al., 2008). The basic assumption behind this focus is that the disposition most closely linked to the performance of volitional action is the intention to engage in this action (Ajzen, 2002b). Studies testing the intention -action relationship are still scarce but nevertheless supportive (Autio et al., 2001; Kolvereid \& Isaksen, 2006).

\section{Practical Implications}

Entrepreneurship is one of the most important factors contributing to economic and social development, i.e. it is a main driver of employment creation and national wealth (Van Praag \& Versloot, 2007). Consequently many policy initiatives attempt to pull people towards an entrepreneurial career choice (European Commission, 2003). On the individual level, moreover, entrepreneurship is a highly satisfying career choice (Gorgievski, Bakker \& Schaufeli, 2010; Stephan \& Roesler, 2009; Van Praag \& Versloot, 2007). The present study provides some implications for interventions aiming to increase the entrepreneurial intentions of students that should work across countries.

Given the close association of attitudes and self-efficacy with intentions across all countries in our sample, education programs should pay particular attention to positively influencing students' attitudes towards entrepreneurial activity and increasing their selfefficacy for creating a new firm. Activities that further enable such learning experiences may include establishing contacts between students and entrepreneurs who may be good role models, and role models are known to positively influence self-efficacy and likely also influence attitudes towards entrepreneurship more positively.

\section{References}

Abrams, D., Ando, K., and Hinkle, S. W. (1998). Psychological attachment to the group: Cross cultural differences in organizational identification and subjective norms as predictors of turnover intentions. Personality and Social Psychology Bulletin, 24, $1027-$ 1039. 
Ajzen, I. (1991). Theory of planned behavior. Organizational Behavior and Human Decision Processes, 50, 179-211.

Ajzen, I. (2002a). Constructing a TPB questionnaire: conceptual and methodological considerations. Retrieved from http://www.people.umass.edu/aizen/

Ajzen, I. (2002b). Perceived behavioral control, self-efficacy, locus of control and the theory of planned behavior. Journal of Applied Social Psychology, 32, 1-20.

Ajzen, I., \& Fishbein, M. (1980). Understanding attitudes and predicting social behavior. Englewood Cliffs, NJ: Prentice-Hall.

Arbuckle, J. L. (2006). AMOS (version 6.0). Chicago: SmallWaters.

Armitage, C. J., \& Conner, M. (2001). Efficacy of the theory of planned behaviour: a metaanalytic review. British Journal of Social Psychology, 40, 471-499.

Autio, E., Keeley, R. H., Klofsten, M., Parker, G. G. C., \& Hay, M. (2001). Entrepreneurial intent among students in Scandinavia and in the USA. Enterprise and Innovation Management Studies, 2(2), 145-160.

Bandura, A. (1982). Self-efficacy mechanism in human agency. American Psychologist, 37, 122-147.

Bandura, A. (2001). Social cognitive theory: an agentic perspective. Annual Review of Psychology, 52(1), 1-26.

Baron, R. A. (2004). The cognitive perspective: a valuable tool for answering entrepreneurship's basic "why" questions. Journal of Business Venturing, 19(2), 221-239.

Beck, L., \& Ajzen, I. (1991). Predicting dishonest actions using the theory of planned behavior. Journal of Research in Personality, 25, 285-301.

Begley, T. M., \& Tan, W.-L. (2001). The socio-cultural environment for entrepreneurship: A comparison between East Asian and Anglo-Saxon countries. Journal of International Business Studies, 32(3), 537-553.

Behrend, T. S., Thompson, L.F., Meade, A. W., Newton, D. A., \& Grayson, M. S. (2008). Measurement invariance in careers research: using IRT to study gender differences in medical students' specialization decisions. Journal of Career Development, 35(1), 60-83. doi: $10.1177 / 0894845308317936$ 
Bird, B. (1988). Implementing entrepreneurial ideas: the case for intentions. Academy of Management Review, 13(3), 442-453.

Bosma, N., Acs, Z. J., Autio, E., Coduras, A., \& Levie, J. (2008). Global Entrepreneurship Monitor. 2008 Executive Report. Retrieved from http://www.gemconsortium.org/

Brown, D. (2002). The role of work and cultural values in occupational choice, satisfaction, and success: A theoretical statement. Journal of Counseling \& Development, 80, 48-56.

Brown, T. (2006). Confirmatory factor analysis for applied research methodology in the social sciences. New York: The Guilford Press.

Browne, M. W., \& Cudeck, R. (1992). Alternative ways of assessing model fit. Sociological Methods and Research, 21, 230-258.

Byrne, B. (2001). Structural equation modeling with AMOS, EQS, and LISREL. International Journal of Testing, 1(1), 55-86.

DeVellis, R. F. (1991). Scale development: theory and applications. Newbury Park, CA: Sage.

Douglas, E. J., \& Shepherd, D. A. (2002). Self-employment as a career choice: attitudes, entrepreneurial intentions, and utility maximization. Entrepreneurship Theory and Practice, 26(3), 81-90.

Douglas, S.P., \& Craig, C.S. (2007). Collaborative and iterative translation: an alternative approach to back translation. Journal of International Marketing, 15, 30-43.

European Commission (2003). Green paper "Entrepreneurship in Europe". Retrieved from http://www.europa.eu.int/comm/enterprise/entrepreneurship/green_paper

Flores, L.Y., Robitschek, C., Celebi, E., Andersen, C., \& Hoang, U. (2010). Social cognitive influences on Mexican Americans' career choices across Holland's themes. Journal of Vocational Behavior, 76, 198-210. doi: 10.1016/j.jvb.2009.11.002

Gartner, W. B., Shaver, K. G., Gatewood, E. J., \& Katz, J. (1994). Finding the entrepreneur in entrepreneurship. Entrepreneurship Theory and Practice, 18(3), 5-10.

Gird, A., \& Bagraim, J. J. (2008). The theory of planned behavior as predictor of entrepreneurial intent amongst final-year university students. South African Journal of Psychology, 38(4), 711-724. 
Gorgievski, M.J., Bakker A.B., \& Schaufeli, W.B. (2010). Work engagement and workaholism: comparing the self-employed and salaried employees. Journal of Positive Psychology, 5, 83 - 96. doi: 10.1080/17439760903509606

Hagger, M. S., Chatzisarantis, N. L. D., Barkoukis, V., Wang, J. C. K., Hein, V., Pihu, M., et al. (2007). Cross-cultural generalizability of the theory of planned behavior among young people in a physical activity context. Journal of Sport \& Exercise Psychology, 29, 1-20.

Hambleton, R. K. (1994). Guidelines for adapting educational and psychological tests: A progress report. European Journal of Psychological Assessment, 10, 229-244.

Harland, P., Staats, H., \& Wilke, H. (1999). Explaining proenvironmetal intention and behavior by personal norms and the theory of planned behavior. Journal of Applied Social Psychology, 29(2), 505-528.

Hofstede, G. (2001). Culture's consequences: comparing values, behaviors, institutions, and organizations across nations. California: Sage.

House, R. J., Hanges, P. W., Javidan, M., Dorfman, P., \& Gupta, V. (2004). Culture, Leadership and Organizations: The GLOBE Study of 62 Societies. Thousand Oaks, CA: Sage.

Jacob, K., \& Richter, P. G. (2005). Absichten zur gründung eines unternehmens bei studierenden [Students' intentions to found a business]. Wirtschaftspsychologie, 2, 51-70.

Jung, D. I., Ehrlich, S. B., De Noble, A. F., \& Baik, K. B. (2001). Entrepreneurial SelfEfficacy and its Relationship to Entrepreneurial Actions: A Comparative Study Between the US and Korea. Management International, 6(1), 41-53.

Kolvereid, L. (1996). Prediction of employment status choice intentions. Entrepreneurship Theory and Practice, 21(1), 47-58.

Kolvereid, L., \& Isaksen, E. (2006). New business start-up and subsequent entry into selfemployment. Journal of Business Venturing, 21(6), 866-885.

Krueger, N.F. (2000). The cognitive infrastructure of opportunity emergence. Entrepreneurship Theory \& Practice, 24, 5-23.

Krueger, N. F., Jr., \& Carsrud, A. L. (1993). Entrepreneurial intentions: applying the theory of planned behavior. Entrepreneurship and Regional Development, 5, 316-323. 
Krueger, N. F., Jr., Reilly, M. D., \& Carsrud, A. L. (2000). Competing models of entrepreneurial intentions. Journal of Business Venturing, 15, 411-432.

Kuehn, K. W. (2008). Entrepreneurial intentions research: Implications for entrepreneurship education. Journal of Entrepreneurship Education, 11, 87-98.

Laguna, M., Moriano, J.A., Roznowki, B., \& Gómez, A. (2008). Entrepreneurship in Polish and Spanish students explained by means of the theory of planned behavior. Studia Psychologiczne (Psychological Studies), 46, 27-40.

Lent, R. W., Brown, S. D., \& Hackett, G. (2000). Contextual supports and barriers to career choice: A social cognitive analysis. Journal of Counseling Psychology, 47(1), 36-49.

Leong, F.T.L. (2010). A Cultural Formulation Approach to Career Assessment and Career Counseling: Guest Editor's Introduction. Journal of Career Development, 37, 375-390. doi: $10.1177 / 0894845310363708$

Liñán, F., \& Chen, Y.-W. (2009). Development and cross-cultural application of a specific instrument to measure entrepreneurial intentions. Entrepreneurship Theory and Practice, 33(3), 593-617. doi: 10.1111/j.1540-6520.2009.00318.x

Malach-Pines, A. \& Kaspi-Baruch, O. (2008). The role of culture and gender in the choice of a career in management. Career Development International, 13, 306-319. doi: $10.1108 / 13620430810880808$

Markus, H. R., \& Kitayama, S. (2003). Culture, self, and the reality of the social. Psychological Inquiry, 14(3), 277-283.

Moriano, J. A. (2005). El perfil psicosocial del emprendedor [The psychosocial profile of the entrepreneur]. Madrid: Consejo Económico y Social.

Oysermann, D. \& Lee, S.W.S. (2008). A Situated cognition perspective on culture. In R.M. Sorrentino \& S. Yamaguchi (eds), Handbook of Motivation and Cognition Across Cultures (p. 237-265). Elsevier.

Rauch, A., \& Frese, M. (2007). Let's put the person back into entrepreneurship research. European Journal of Work and Organizational Psychology, 16, 353-385.

Shane, S. (2008). The illusions of entrepreneurship. Yale, NH: Yale University Press. 
Shapero, A. (1982). Social dimensions of entrepreneurship. In C. A. Kent, D. L. Sexton \& K. Vesper (Eds.), The Encyclopedia of Entrepreneurship (pp. 72-90). Englewood Cliffs: Prentice Hall.

Steenkamp, J.-B. E. M., \& Baumgartner, H. (1998). Assessing measurement invariance in cross-national consumer research. The Journal of Consumer Research, 25(1), 78-90.

Stephan, U., \& Uhlaner, L.M. (2010). Performance based vs. Socially supportive culture: A cross-national study of descriptive norms and entrepreneurship, Journal of International Business Studies, 41, 1347 - 1363. doi: 10.1057/jibs.2010.14.

Stephan, U., \& Roesler, U. (2010). Health of entrepreneurs versus employees in a national representative sample. Journal of Occupational and Organizational Psychology, 83, 717 738. doi:10.1348/096317909X472067

Tiessen, J. H. (1997). Individualism, collectivism, and entrepreneurship. Journal of Business Venturing, 12(5), 367-384.

Tkachev, A., \& Kolvereid, L. (1999). Self-employment intentions among Russian students. Entrepreneurship and Regional Development, 11(3), 269-280.

Triandis, H. C. (1995). Individualism \& collectivism. Oxford: Westview.

van de Vijver, F., \& Leung, K. (2001). Personality in cultural context: Methodological issues. Journal of Personality, 69, 1007-1031.

van Gelderen, M., Brand, M., van Praag, M., Bodewes, W., Poutsma, E., \& van Gils, A. (2008). Explaining entrepreneurial intentions by means of the theory of planned behaviour. Career Development International, 13, 538-559. doi: $10.1108 / 13620430810901688$

Van Praag, C. M., \& Versloot, P. H. (2007). What is the value of entrepreneurship? A review of recent research. Small Business Economics, 29, 351-382. 
Table 1. Sample characteristics (percentages for every variable) and significance of differences test

\begin{tabular}{|c|c|c|c|c|c|c|c|c|}
\hline \multirow{2}{*}{$\begin{array}{l}\text { Sample } \\
\text { characteristic }\end{array}$} & \multicolumn{7}{|c|}{ Sample } & \multirow{2}{*}{$\begin{array}{c}\begin{array}{c}\text { Significance } \\
\text { of differences }\end{array} \\
\chi^{2}\end{array}$} \\
\hline & $\begin{array}{c}\text { Total } \\
\text { sample } \\
(N= \\
1074)\end{array}$ & $\begin{array}{c}\text { Germany } \\
\qquad(N= \\
217)\end{array}$ & $\begin{array}{c}\text { India } \\
(N=86)\end{array}$ & $\begin{array}{l}\text { Iran } \\
(N \\
=114)\end{array}$ & $\begin{array}{c}\text { Poland } \\
(N=291)\end{array}$ & $\begin{array}{c}\text { Spain } \\
(N=227)\end{array}$ & $\begin{array}{c}\text { The } \\
\text { Netherla } \\
\text { nds } \\
(N=139)\end{array}$ & \\
\hline Gender & & & & & & & & $\begin{array}{l}108.08^{* * *} \\
(d f=5)\end{array}$ \\
\hline Men & 57.7 & 47.7 & 89.5 & 37.7 & 47.8 & 73.1 & 65.5 & \\
\hline Women & 42.3 & 52.3 & 10.5 & 62.3 & 52.2 & 26.9 & 34.5 & \\
\hline $\begin{array}{l}\text { Employment } \\
\text { status }\end{array}$ & & & & & & & & $\begin{array}{c}220.80 * * * \\
(d f=10)\end{array}$ \\
\hline Student only & 65.7 & 79.7 & 27.9 & 89.5 & 78.0 & 38.8 & 66.3 & \\
\hline $\begin{array}{l}\text { Company } \\
\text { employed }\end{array}$ & 30.6 & 17.1 & 66.3 & 10.5 & 17.2 & 59.0 & 25.3 & \\
\hline $\begin{array}{l}\text { Self- } \\
\text { employed }\end{array}$ & 3.7 & 3.2 & 5.8 & 0 & 4.8 & 2.2 & 8.4 & \\
\hline Major & & & & & & & & $\begin{array}{l}372.80 * * * \\
(d f=10)\end{array}$ \\
\hline Psychology & 37.8 & 50.2 & 0 & 33.3 & 43.8 & 44.6 & 60.4 & \\
\hline Business & 42.6 & 49.8 & 100 & 66.7 & 23.1 & 15.3 & 22.3 & \\
\hline Other & 19.6 & 0 & 0 & 0 & 33.1 & 40.1 & 17.3 & \\
\hline
\end{tabular}

Note $* * * p<.001$ 
Table 2 The means ${ }^{1}$, standard deviations, and zero-order correlations ${ }^{2}$ between study variables in the total sample and each subsample

\begin{tabular}{lcccccc}
\hline Variables & $M$ & $S D$ & & Zero-order correlations & $M$ & $S D$ \\
& & & 1 & 2 & 3 & 4 \\
\hline
\end{tabular}

\section{Total sample $(\mathrm{N}=\mathbf{1 0 7 4})$}
1. Attitudes
2. Subjective norms
3. Entrepreneurial self-efficacy
4. Entrepreneurial intentions

1. Attitudes

2. Subjective norms

3. Entrepreneurial self-efficacy

4. Entrepreneurial intentions

1. Attitudes

2. Subjective norms

3. Entrepreneurial self-efficacy

4. Entrepreneurial intentions

1. Attitudes

2. Subjective norms

3. Entrepreneurial self-efficacy

4. Entrepreneurial intentions
$2.88 \quad .82$

$2.29 \quad 1.26$

$4.96 \quad 1.04$

$3.80 \quad 1.62$

$.29 * * *$

Germany $(N=217)^{a}$
$2.71 \quad .87$

$2.93 \quad 1.02$

$4.60 \quad 1.08$

$2.99 \quad 1.48$

India $(N=86)^{\text {a }}$

$3.68 \quad .71$

$2.28 \quad 1.17$

$.41 * * *$

$5.65 \quad .98$

$.47 * * *$

$5.051 .58 \quad .54 * * *$

$\operatorname{Iran}(N=114)^{a}$
Poland $(N=291)^{b}$

$.16^{* *}$

$.61 * * *$

$.49 * * * \quad 3.01$

.85

- $.13^{*}$

$.12 * \quad 3.06$

1.04

$.42 * * *$

$.41 * * *$

4.98

.95

$.25^{* * *} \quad .21^{* * *}$

$4.46 \quad 1.42$

Spain $(N=227)^{b}$
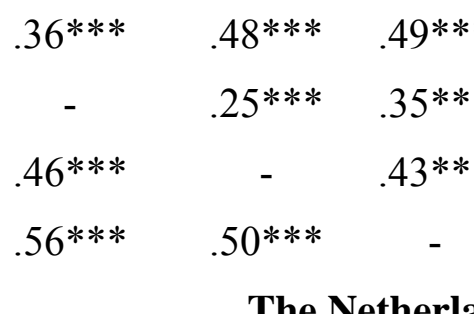

2.74

.87

$2.93 \quad 1.02$

$.43 * * * \quad 4.60 \quad 1.08$

The Netherlands $(N=139)^{b}$

$2.55 \quad 87$

$.37 * * *$
$.39 * *$
$.30 * * *$

$.50 * * *$

2.87

.62

$1.691 .08 \quad .32 * * *$

$5.00 \quad 1.02 \quad .26 * * *$

$.53 * * *$

$1.29 \quad .91$

.18

$4.34 \quad 1.53 \quad .36^{* * *}$

Notes $* * p<.01 ; * * * p<.001$ (two-tailed); ${ }^{\text {a }}$ correlations are presented in the lower triangle;

${ }^{\mathrm{b}}$ correlations are presented in the upper triangle of the correlation's matrix.

\footnotetext{
${ }^{1}$ Note that comparing means across countries was not the aim of this study. Means differences between countries need to be interpreted with caution, because of possible biases related to e.g., scalar inequivalence. Hierarchical multiple regression analyses show that average scores for intentions and subjective norms are significantly different for Germany, India, Iran and The Netherlands as compared to Poland and Spain. Average scores for attitudes, are significantly different for Germany, India and Iran as compared to Poland, The Netherlands and Spain. Average scores for intentions and subjective norms, and self-efficacy are significantly different for India and The Netherlands as compared to India, Iran, Poland and Spain. These differences are significant after controlling for demographic differences and data collection methods.
}

${ }^{2}$ Differences between the strength of relationships across countries will be tested further. 
Table 3. Model fit with all parameters estimated freely across countries ("configural invariance, but no metric invariance”), as compared to models assuming complete or partial metric invariance (equal factor loadings) across countries. Results presented per scale.

\begin{tabular}{|c|c|c|c|c|c|c|c|c|c|}
\hline \multirow[t]{2}{*}{ Variables } & \multirow[t]{2}{*}{ Models } & \multicolumn{6}{|c|}{ Model fit } & \multicolumn{2}{|c|}{$\begin{array}{l}\text { Model fit compared to } \\
\text { "no metric invariance" }\end{array}$} \\
\hline & & $\chi^{2}$ & $d f$ & NFI & NNFI & CFI & RMSEA & $\Delta \chi^{2}$ & $d f$ \\
\hline \multirow[t]{3}{*}{ Attitudes } & Configural invariance & 67.73 & 46 & .96 & .96 & .98 & .02 & & \\
\hline & Partial metric invariance & $98.89^{*}$ & 68 & .94 & .96 & .98 & .02 & $31.17 \mathrm{~ns}$ & 20 \\
\hline & Full metric invariance & $138.58 * * *$ & 71 & .91 & .91 & .95 & .03 & $70.85 * * *$ & 25 \\
\hline \multirow[t]{3}{*}{ Subjective norms } & Configural invariance & -- & 0 & -- & -- & -- & -- & & \\
\hline & Partial metric invariance & $8.84 \mathrm{~ns}$ & 8 & .99 & 1.00 & 1.00 & .00 & $8.84 \mathrm{~ns}$ & 8 \\
\hline & Full metric invariance & $27.08 * *$ & 10 & .98 & .96 & .99 & .04 & $27.07 * *$ & 10 \\
\hline \multirow[t]{3}{*}{ Entrepreneurial self-efficacy } & Configural invariance & $17.40 \mathrm{~ns}$ & 12 & .99 & .96 & 1.00 & .02 & & \\
\hline & Partial metric invariance & $39.61 \mathrm{~ns}$ & 31 & .98 & .98 & 1.00 & .02 & $22.21 \mathrm{~ns}$ & 19 \\
\hline & Full metric invariance & $53.26^{*}$ & 32 & .97 & .97 & .99 & .02 & $35.86^{*}$ & 20 \\
\hline \multirow[t]{3}{*}{ Entrepreneurial intentions } & Configural invariance & $14.89 \mathrm{~ns}$ & 7 & .99 & .96 & 1.00 & .03 & & \\
\hline & Partial metric invariance & 33.26 & 18 & .98 & .97 & .99 & .03 & $18.37 \mathrm{~ns}$ & 11 \\
\hline & Full metric invariance & $72.60 * * *$ & 22 & .96 & .93 & .97 & .05 & $57.71 * * *$ & 15 \\
\hline
\end{tabular}


Table 4. Standardized (upper) and unstandardized (lower) parameter estimates with standard error (in brackets) among TPB model factors.

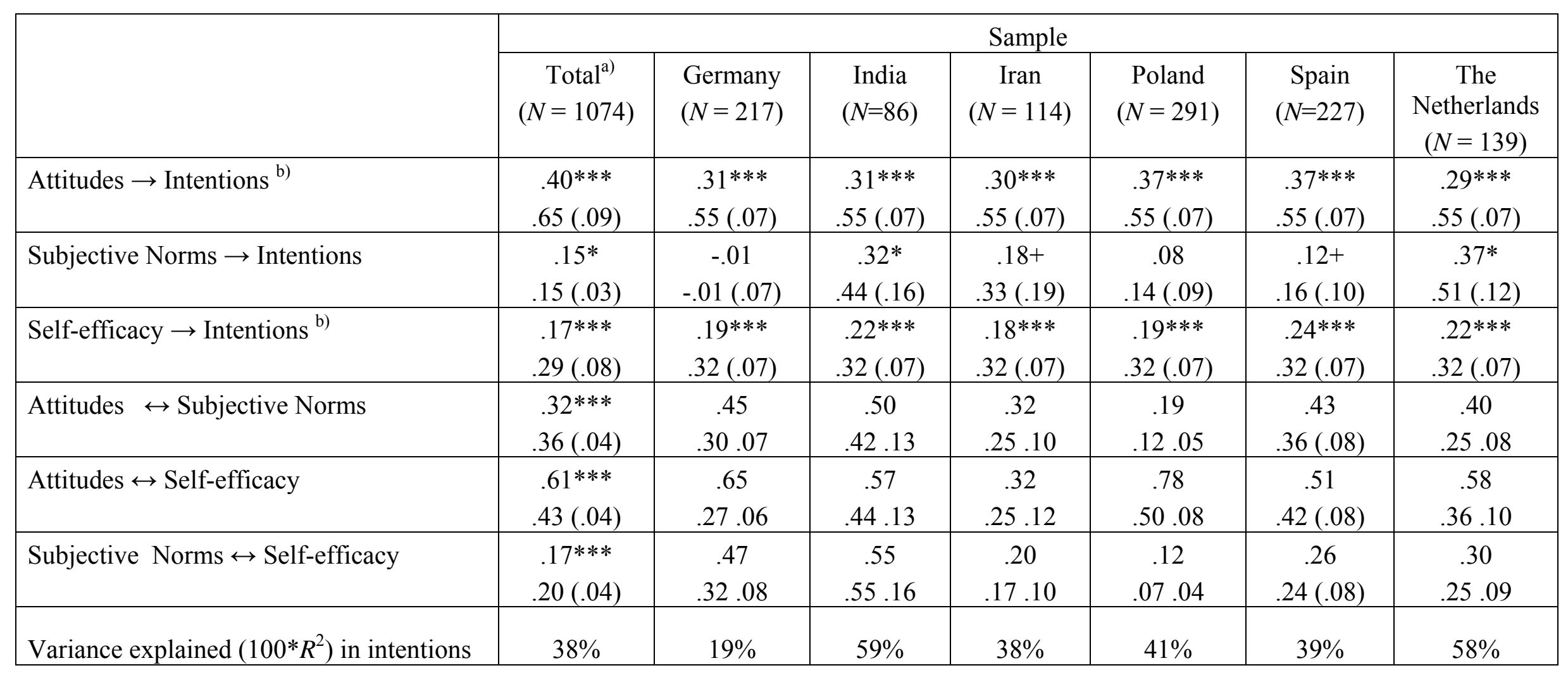

${ }^{+} p<.10 ; * p<.05 ; * * p<.001$; a) All models controlled for gender, age, major and employment status. b) Cross-country differences are not significant, hence the standardized parameter is constrained equal for all countries. 